\title{
AN INVESTIGATION OF SHALLOW WATER FLOW OVER PERMEABLE BED WITH REFERENCE TO SURFACE IRRIGATION
}

\section{Hassan I. Mohamed}

Civil Engineering Department, Faculty of Engineering, Assiut University, Assiut, Egypt

Email: hassanmohamed 2000@yahoo.com

(Received January 16, 2006 Accepted February 28, 2006)

Surface irrigation is used more than pressurized irrigation due to low cost, more efficient energy requirements, and better aeration of the root zone. The design, evaluation and simulation of surface irrigation systems rely on a knowledge of the movement of the water over the field. However, hydraulics of surface irrigation flow is more complicated flow than the other open channel flow due to the shallowness and unsteadiness of water depth and existence of permeable bed. In application of the volume balance (VB) models, it is generally assumed that the average depth of surface water is constant. This basic assumption may cause significant errors in computing advance water. In this paper, a model is developed for computing the advance distance and/or time of propagation for both border and furrow irrigation. Where, the surface and subsurface flow profiles in the advance phase are assumed to be of parabolic shape and their coefficients are determined by conditions in the gradually varied flow region, rather than in the rapidly varied flow region near the advance front. The model is applied for both border and furrow irrigation. The results are satisfied via testing with the field data obtained from different regions and various soil types and situation of field surface.

KEYWORDS: gradually varied flow; surface irrigation; advance distance; propagation time; infiltration.

\section{NOMENCLATURE}

$A_{i}=$ the furrow subsurface profile cross sectional area,

$A_{s}=$ the furrow cross sectional area of surface flow,

$H=$ the subsurface water depth,

$h=$ the surface water depth,

$I=$ the infiltration rate,

$n$ = Manning's roughness coefficient,

$Q_{0}=$ the furrow discharge, 
$q_{0}=$ border discharge per unit width,

$S=$ advance front position from the upstream end,

$S_{0}=$ the bed slope,

$t$ = time of advance,

$T_{s}=$ the total inflow time,

$V_{s a}=$ volume of water remaining on the surface,

$V_{i a}=$ volume of water stored in subsurface,

$x=$ the distance along the soil surface from the upstream end.

\section{INTRODUCTION}

Surface irrigation is the most widely used irrigation method in the world. Adequate prediction of the advance irrigation phase is important in surface irrigation system design and evaluation. Poor designs and management are generally responsible for inefficient irrigation and low application efficiency, leading to wastage of water, water-logging, salinization and pollution of surface water and ground water resources. Non-uniform application of water results in water-stressed conditions for crops in some parts of the field, while over-irrigation leads to wastage of water through runoff from the end of the field and deep percolation below the root zone. When modeling of surface irrigation, there are additional numerical challenges which are not found in other situations, Hauke [1]. These challenges include (i) very small water levels, $h$, (ii) advance and recession waves over a dry bed, $h=0$, (iii) large friction coefficients and singular friction terms which become unbounded as $h \rightarrow 0$, (iv) very large and singular infiltration terms.

Many researchers studied the surface irrigation from different points of view. Among them are Strelkoff and Bjorneberg [2], Nasseri et al. [3], Abbasi et al. [4], Rasoulzadeh and Sepaskhah [5] and Eldeiry et al. [6]. Esfandiari and Maheshwari [7] evaluated four furrow irrigation models using field data and concluded that there is small deviation between them. Valiantzas $[8,9]$ studied the variation of subsurface and surface shape factor for the advance water profile and suggested a method for computing the propagation time based on these factors. Playán et al. $[10,11]$ have deduced a two-dimensional model for simulation of basin irrigation. Zapata and Playán [12] examined the effect of spatial variability of infiltration and soil surface elevation on surface irrigation performance. Clemmens [13] developed a procedure to estimate the advance and infiltration equations corresponding to untested discharges in furrow irrigation. Holzapfer et al. [14] analyzed four different methods to determine the infiltration constants of the Kostiakov model. Maheshwari and McMahon [15] based on both experimental and field data showed that the discharge-depth equation is a more suitable model than the Manning's equation for the shallow flow. From the previous studies, it was found that the most models either based average water depth or solving complicated Saint-Venant equation and to the author knowledge there is not a quasi 1-D model for flow in furrow irrigation.

The main objective of this study is to develop, a simple, easy to apply and sufficiently accurate model predicting the surface and subsurface advance phase i.e. 
advance distance, time of propagation and water profiles in both border and furrow irrigation. This model takes into account the variation of the surface and subsurface water profiles along the field.

\section{THEORETICAL ANALYSIS}

Surface irrigation flow is considered unsteady and spatially varied open channel flow. In this paper, a model is developed for computing propagation time or advance distance and surface and subsurface longitudinal water flow profiles for both border and furrow irrigation. In this model, the following assumptions are made: (1) the inflow is steady; (2) the border or furrow is homogeneous (i.e. its slope, width, and composite roughness do not vary with location); (3) the border is sufficiently wide so that the side effects can be neglected; and (4) bed slope is so small that $\sin \alpha \cong \tan \alpha \cong S_{0}$ and $\cos \cong 1$, where $\alpha$ is the angle that the border or furrow makes with the horizontal plane. Additionally, the surface and subsurface longitudinal flow profiles in the advance phase are assumed to be of parabolic shape, and their coefficients are determined by conditions in the gradually varied flow region, rather than in the rapidly varied flow region near the advance front. Meanwhile, it is assumed that the flow in the region from the upstream end to section that is $2 \mathrm{~m}$ behind the front is gradually varied.

For an irrigation border, let a unit width constant inflow be $q_{0}\left(\mathrm{~m}^{3} / \mathrm{min} / \mathrm{m}\right)$, introduced at the head. Let the advance front position be denoted as $S(\mathrm{~m})$, for a given time $t(\mathrm{~min})$. The integral form of continuity equation can be expressed as:

$$
q_{0} t=\int_{0}^{S} h(x, t) d x+\int_{0}^{S} H(x, t) d x
$$

and the continuity for furrow irrigation can be expressed in the following form:

$$
Q_{0} t=\int_{0}^{S} A_{s}(x, t) d x+\int_{0}^{S} A_{i}(x, t) d x
$$

where $x(\mathrm{~m})$ is the distance along the soil surface from the upstream end $(0 \leq x \leq S) ; h(x, t)$ and $H(x, t)$ the surface and subsurface water profiles depth, respectively, $Q_{0}$ is the furrow discharge $\left(\mathrm{m}^{3} / \mathrm{min}\right)$, and $A_{s}(x, t)$ and $A_{i}(x, t)$ are the surface and subsurface water profiles cross sectional area of furrow, respectively, because of the two dimensionality of surface irrigation. The surface water longitudinal profile depth $(0 \leq x \leq S)$ is assumed to be of parabolic form:

$$
h(x, t)=h_{0}\left(a_{1} x^{2}+b_{1} x+c_{1}\right)
$$

by the same way, the surface water longitudinal profile area for furrow can be assumed to be of parabolic form:

$$
A_{s}(x, t)=A_{s 0}\left(a_{1} x^{2}+b_{1} x+c_{1}\right)
$$


where $a_{1}, b_{1}, c_{1}$ are three coefficients that are functions of time only; and $h_{0}(\mathrm{~m})$ is the normal inflow depth for border irrigation flow and $A_{s 0}\left(\mathrm{~m}^{2}\right)$ is the normal flow area for furrow irrigation, and can be computed by Manning's Eqn. (3), and the upstream boundary conditions may be written as in Eqs. (4) and (5).

$$
\begin{aligned}
& h_{0}=\left(\frac{n q_{0}}{60 S_{0}^{1 / 2}}\right)^{3 / 5} \\
& A_{s 0}=\left(\frac{n Q_{0}}{p_{1} S_{0}^{1 / 2}}\right)^{1 / p_{2}} \\
& h(0, t)=h_{0}, \quad 0 \leq t \leq T_{s} \\
& A_{s}(0, t)=A_{s 0}, \quad 0 \leq t \leq T_{s} \\
& \frac{\partial h(0, t)}{\partial x}=0, \quad 0 \leq t \leq T_{s} \\
& \frac{\partial A_{s}(0, t)}{\partial x}=0, \quad 0 \leq t \leq T_{s}
\end{aligned}
$$

where $n$ is Manning's roughness coefficient; $S_{0}$ the bed slope; while $p_{1}$ and $p_{2}$ are the coefficients depending on the furrow geometry, and $T_{s}$ the total inflow time. Although Eqn. (5) is an approximation, it would deviate little from reality because the surface flow rate is much faster than infiltration rate. Hence, the opportunity times in the neighborhood of the upstream end are nearly equal. For many practical border and furrow slopes, the normal flow depth can soon be maintained in the neighborhood of the upstream end. Because the flow near the advance front is rapidly varied, the flow condition at the front cannot reflect the gradually varied flow profile behind the front. It may be preferable to find the third condition to determine the three coefficients in Eqn. (2) in the gradually varied flow region. As the last assumption mentioned above, Kostiakov infiltration equation is employed as

$$
H=K t^{\alpha}+c t
$$

where $H(\mathrm{~m})$ is the infiltrated water depth, and $K\left(\mathrm{~m} / \mathrm{min}^{\alpha}\right), \alpha$ (dimensionless), and $c(\mathrm{~m} / \mathrm{min})$ the three constant coefficients that can be determined by field experiments. As a matter of fact, only two coefficients suffice, thus, reducing work in the field. So, it may be expressed as

$$
H=K t^{\alpha}
$$

For uniform advance, the opportunity time along the border or furrow is linear so that the average infiltration rate for an advance distance $S$ and time $t$ can be calculated by using Eqn. (8) as 


$$
I=\frac{1}{t} \int_{0}^{t} K \alpha t^{\alpha-1} d t=k t^{\alpha-1}
$$

For gradually varied flow, Eqn. (9) may be employed by multiplying a non-uniform flow coefficient $f$ (dimensionless) so that the flow rate at the section $x=S-2, q_{2}\left(\mathrm{~m}^{3} / \mathrm{min} / \mathrm{m}\right)$ may be estimated by neglecting the rate of change of surface storage in the range of $0 \leq x \leq S-2$.

$$
q_{2}=q_{0}-f I(S-2)
$$

where the non-uniform flow coefficient $f$ was calibrated, Li and Zhang [16]. The value of $f=0.35$ gave the least sum of squared errors between observed and computed values, Yu and Singh [17].

On the other hand, $q_{2}$ can be computed by Manning's equation as;

$$
q_{2}=\frac{60 S_{0}^{1 / 2} h_{2}^{5 / 3}}{n}
$$

Equating Eqns. (9) and (10) yields the water depth at downstream end ( $2 \mathrm{~m}$ behind the front) as:

$$
h_{2}=\left\{\left[q_{0}-f K t^{\alpha-1}(S-1)\right] \frac{n}{60 S_{0}^{1 / 2}}\right\}^{3 / 5}
$$

and by the same way for furrow irrigation, the flow cross-sectional area at downstream end ( $2 \mathrm{~m}$ behind the front) can be computed as follow:

$$
A_{s 2}=\left\{\left[Q_{0}-f K t^{\alpha-1}(S-2)\right] \frac{n}{p_{1} S_{0}^{1 / 2}}\right\}^{1 / p_{2}}
$$

Therefore the third boundary condition can be given as

$$
h(S-2, t)=h_{2}
$$

And

$$
A_{s}(S-2, t)=A_{s 2}
$$

Application of Eqns. (4), (5) and (11) to Eqn. (2) produces

$$
a_{1}=\frac{-\left(h_{0}-h_{2}\right)}{h_{0}(S-2)^{2}}
$$




$$
\begin{aligned}
& b_{1}=0 \\
& c_{1}=1
\end{aligned}
$$

Hence, the surface water profile becomes for border and furrow irrigation, respectively.

$$
\begin{gathered}
h(x, t)=h_{0}-\frac{\left(h_{0}-h_{2}\right) x^{2}}{(S-2)^{2}} \\
A_{s}(x, t)=A_{s 0}-\frac{\left(A_{s 0}-A_{s 2}\right) x^{2}}{(S-2)^{2}}
\end{gathered}
$$

Then the volume of water remaining on the surface per unit width, $V_{s a}\left(\mathrm{~m}^{3} / \mathrm{m}\right)$, for an advance distance $S$ and time $t$ is

$$
V_{s a}=\int_{0}^{S} h(x, t) d x=S h_{0}-\frac{\left(h_{0}-h_{2}\right) S^{3}}{3(S-2)^{2}}
$$

and for furrow irrigation

$$
V_{s a}=\int_{0}^{S} A_{s}(x, t) d x=S A_{s 0}-\frac{\left(A_{s 0}-A_{s 2}\right) S^{3}}{3(S-2)^{2}}
$$

Similarly, the subsurface water profile is also assumed to be of parabolic form

$$
H(x, t)=H_{0}\left(a_{2} x^{2}+b_{2} x+c_{2}\right)
$$

where $H_{0}(\mathrm{~m})$ is the infiltrated water depth at the upstream end for a given time $t$ and can be computed by Eqn. (7), and $a_{2}, b_{2}$, and $c_{2}$ the three coefficients that are functions of time only. The upstream end boundary conditions may be specified as

$$
\begin{gathered}
H(0, t)=H_{0} \\
\frac{\partial H(0, t)}{\partial x}=0
\end{gathered}
$$

Since the flow at the section that is $2 \mathrm{~m}$ behind the front was assumed to be gradually varied, the mean velocity, $v_{2}$, at this section may be computed by Manning's equation as

$$
v_{2}=\frac{q_{2}}{h_{2}}=\frac{60 S_{0}^{1 / 2} h_{2}^{2 / 3}}{n}
$$


The opportunity time, $t_{2}$, at the section $x=S-2$ may be estimated by assuming that the mean velocity from $x=S-2$ to $x=S$ is one half of the flow velocity at section $x=S-2$

$$
t_{2}=\frac{2}{0.5 v_{2}}=\frac{n}{15 S_{0}^{1 / 2} h_{2}^{2 / 3}}
$$

Therefore, the infiltrated water depth at section $x=S-2, H_{2}$ is presented as

$$
H_{2}=K\left(\frac{n}{15 S_{0}^{1 / 2} h_{2}^{2 / 3}}\right)^{\alpha}
$$

and for furrow irrigation

$$
H_{2}=K\left(\frac{n}{15 S_{0}^{1 / 2} p_{1} A_{s 2}^{\left(p_{2}-1\right)}}\right)^{\alpha}
$$

Then the cross-sectional area of subsurface furrow irrigation $A_{i 2}$ can be easily computed by multiplying $\mathrm{H}_{2}$ in furrow top width.

Application of Eqns. (17), (18) and (21) yields the coefficients $a_{2}, b_{2}$, and $c_{2}$ as

$$
\begin{aligned}
& a_{2}=\frac{-\left(H_{o}-H_{2}\right)}{H_{o}(S-2)^{2}} \\
& b_{2}=0.0 \\
& c_{2}=1.0
\end{aligned}
$$

Hence, the subsurface water profile may be expressed as

$$
H(x, t)=H_{o}-\frac{\left(H_{o}-H_{2}\right) x^{2}}{(S-2)^{2}}
$$

and the volume of water stored in subsurface is

$$
V_{i a}=\int_{0}^{S} H(x, t) d x=S H_{o}-\frac{\left(H_{o}-H_{2}\right) x^{3}}{3(S-2)^{2}}
$$

and for furrow irrigation

$$
V_{i a}=\int_{0}^{S} A_{i}(x, t) d x=S A_{i_{o}}-\frac{\left(A_{i_{o}}-A_{i 2}\right) x^{3}}{3(S-2)^{2}}
$$


Substituting Eqns. (15) and (24) into Eqn. (1) yields the solution of advance function for border and furrow irrigation, respectively.

$$
\begin{aligned}
& q_{0} t=h_{0} S\left[1-\frac{\left(h_{0}-h_{2}\right) S^{2}}{3 h_{0}(S-2)^{2}}\right]+H_{0} S\left[1-\frac{\left(H_{0}-H_{2}\right) S^{2}}{3 H_{0}(S-2)^{2}}\right] \\
& Q_{0} t=A_{s 0} S\left[1-\frac{\left(A_{s 0}-A_{s 2}\right) S^{2}}{3 A_{s 0}(S-2)^{2}}\right]+A_{i 0} S\left[1-\frac{\left(A_{i 0}-A_{i 2}\right) S^{2}}{3 A_{i 0}(S-2)^{2}}\right]
\end{aligned}
$$

Eqn. (25) is an implicit function of $S$ for a given advance time $t$, or vice versa. This equation can be easily solved by iteration. Procedure of solution is shown in the following chapter.

\section{MODEL VALIDATION AND APPLICATIONS}

One of the major constraints to the improvement of surface irrigation performance has been the difficulty in assessing the many variables associated with surface irrigation systems and their interactions, and to utilize these in irrigation management. In this section procedure of solution, validation and application of the model will be introduced.

\subsection{Procedure of Solution for Time of Propagation}

In summary the proposed procedure to solve the volume balance equation for time of propagation to advance distance $S$, as follows:

1. For any advance distance $S$, assume an initial value for the propagation time $t$.

2. Calculate $h_{0}$ from Eqn. (3-a) for border irrigation flow and $A_{s_{0}}$ from Eqn. (3-b) for furrow irrigation.

3. Calculate $h_{2}$ from Eqn. (11-a) for border irrigation flow and $A_{s 2}$ from Eqn. (11-b) for furrow irrigation.

4. Calculate $H_{0}$ from Eqn. (7).

5. Calculate $H_{2}$ from Eqn. (21-a) for border irrigation flow and from Eqn. (21-b) for furrow irrigation.

6. Calculate value of $t$ from Eqn. (25-a) for border irrigation or Eqn. (25-b) for furrow irrigation.

7. If $t$ in step 6 equals to that in step 1 then stop the calculation, else assume new value for $t$.

8. Then, the surface and subsurface water profile for any advance distance $S$ can be computed using equation (14) and (23), respectively.

\subsection{Border Irrigation}

It is well known that uniformity of distribution of infiltration water along the length of a graded border depends upon the extent to which infiltration opportunity time is constant over the length of the border. The first step towards prediction of this time duration between the advance and recession curves lies in calculation of the 
advance curve for any given inflow rate applied to any given border strip. In the following, the results of the model are compared and verified with field experiment. Where, two border irrigation events were evaluated in order to provide field data to support the theoretical developments, for more details about the field experiments can be found in Playán and Walker [18]. In the first field experiment, the field was $465 \mathrm{~m}$ long by $100 \mathrm{~m}$ wide, with an area of $46,500 \mathrm{~m}^{2}$, and was irrigated from one of its 100 m sides. The infiltration parameters were: $K=0.00893\left(\mathrm{~m} / \mathrm{min}^{\alpha}\right), \alpha=0.406$. A value of 0.1 was estimated for the Manning's $n$. The field was irrigated with a constant discharge of $0.183 \mathrm{~m}^{3} / \mathrm{s}$ and the inflow was cut off after $660 \mathrm{~min}$. The second experiment was performed in a rectangular field. The dimensions of the field were $216.1 \mathrm{~m}$ long by $183.2 \mathrm{~m}$ wide with an area of $39,590 \mathrm{~m}^{2}$. The infiltration parameters were: $K=0.0168\left(\mathrm{~m} / \mathrm{min}^{\alpha}\right), \alpha=0.397$. A value of 0.10 was estimated for the Manning roughness coefficient. The field was irrigated with a constant discharge of $0.270 \mathrm{~m}^{3} / \mathrm{s}$. The inflow was cut off after $540 \mathrm{~min}$.

Figure 1 shows values of advance distance $(S)$ versus propagation time $(t)$ at different bed slope values of $0.05,0.014,0.001$, and $0.0005 \%$ respectively for first field border experiment. It is noticeable that the field bed slope has a large effect on the propagation time, where at the same propagation time the advance distance increases by increasing the bed slope. However, the bed slope must be lower than the critical value for soil erosion. As shown in that Fig., it is found that the field experiment data of Playán and Walker [18] are in well agreement with the computed ones for bed slope $0.014 \%$.

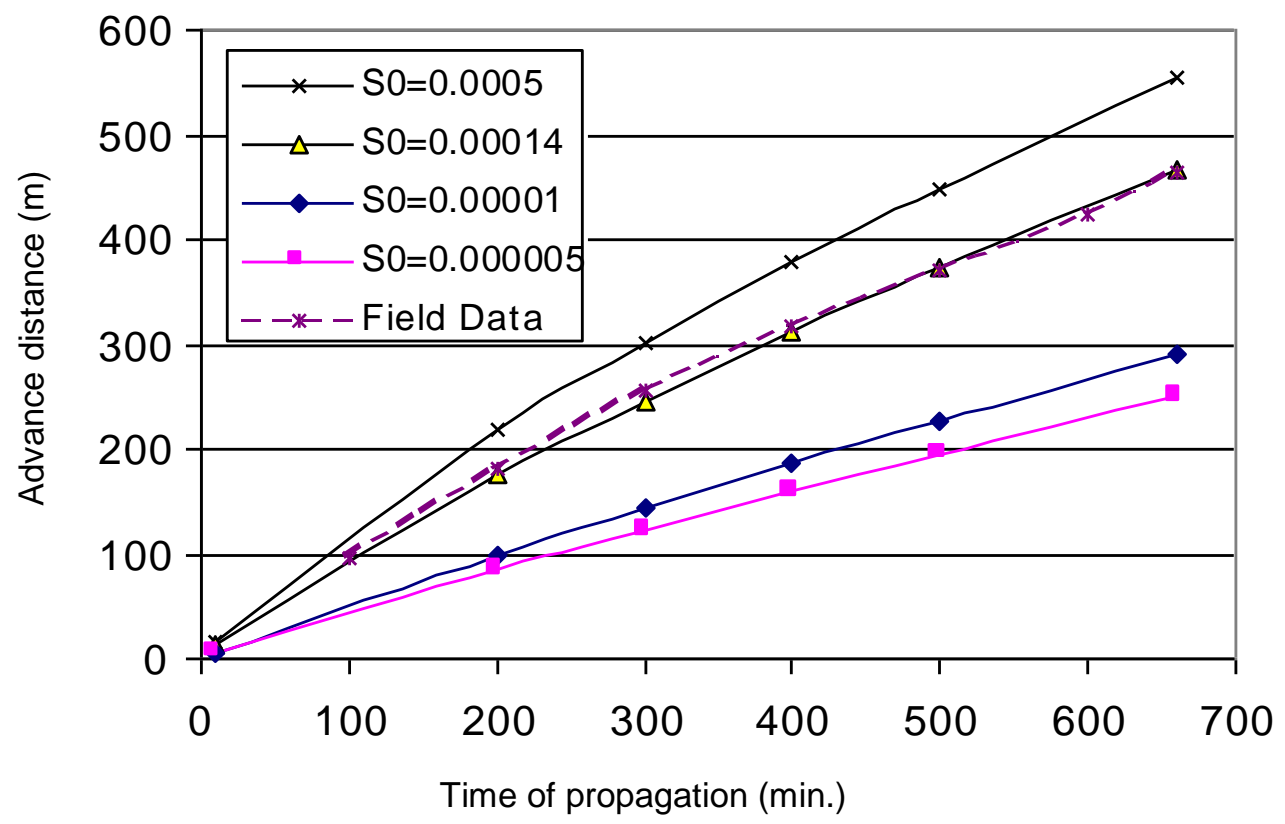

Fig. 1. Advance distance versus time of propagation for first field border experiment at different bed slopes and constant discharge. 
By the same way, Fig. 2 shows values of advance distance $(S)$ versus propagation time $(t)$ for the second field border experiment at bed slope values equal to $0.01,0.007,0.001$, and $0.0005 \%$, respectively. It is noticeable that the field data is in well agreement with the computed one for bed slope equal to $0.007 \%$. It can be seen from that figure that by increasing the bed slope the water can be propagated to a longer distance at the same time. However, irrigation runs that are too long result in over-watering at the top of the border by the time the lower end is adequately watered. Hence, the different parameters controlling irrigation flow must be optimized to minimize the volume of water applied to the field.

AN INVESTIGATION OF SHALLOW WATER FLOW OVER shows the surface and longitudinal subsurface water profiles at different propagation times for the first border experiment and field slope equal to $0.014 \%$. The elevation of the water $h$ is depicted in the positive portion of the vertical axis, whereas the infiltration depth $H$ is shown in the negative portion of the plot. It is noticeable that the infiltration depth increases by increasing the time of propagation. Also, it is noticeable that the variation in the surface water depth is so small compared with the variation in the subsurface water depth with time. In comparison between Fig. 3 and Fig. 4, it is evidently appeared the effect of the soil properties on the infiltration rates.

\subsection{Furrow Irrigation}

The furrow flow is more complicated than the border flow due to the twodimensionality of the flow. In the following, the results of quasi one dimensional model are verified and compared by field experiments. Where, twelve furrow irrigation events were evaluated in order to provide field data to support the theoretical developments. The experiments were performed in four different locations differing in soil types, longitudinal slopes and furrow geometries, for more details can be found in

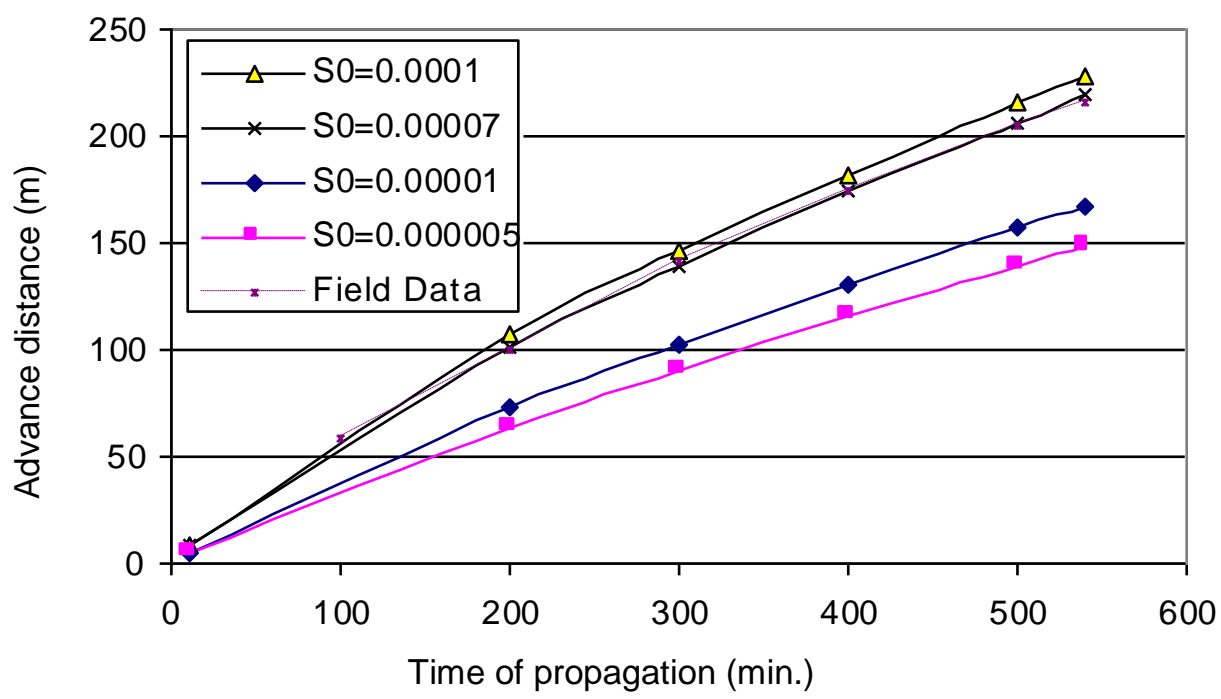

Fig. 2: Advance distance versus time of propagation for second field border experiment at the different bed slopes and constant discharge. 


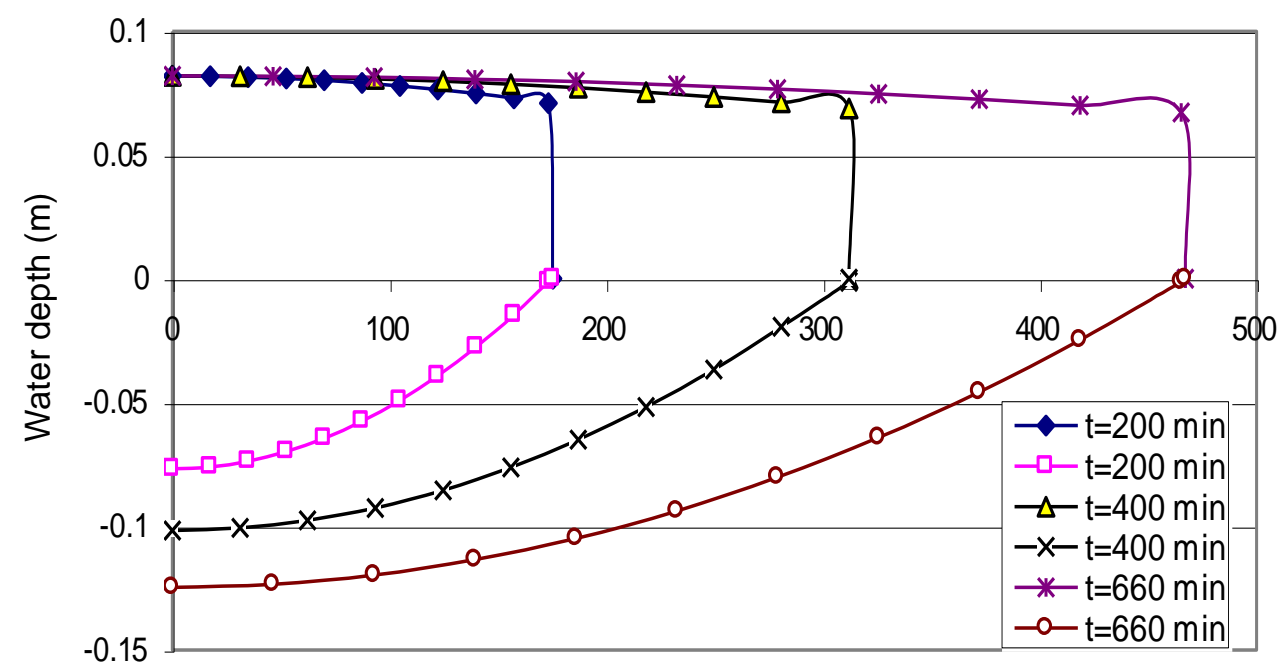

Advance distance (m)

Fig. 3. Surface and subsurface water profiles at different propagation time for the first border experiment.

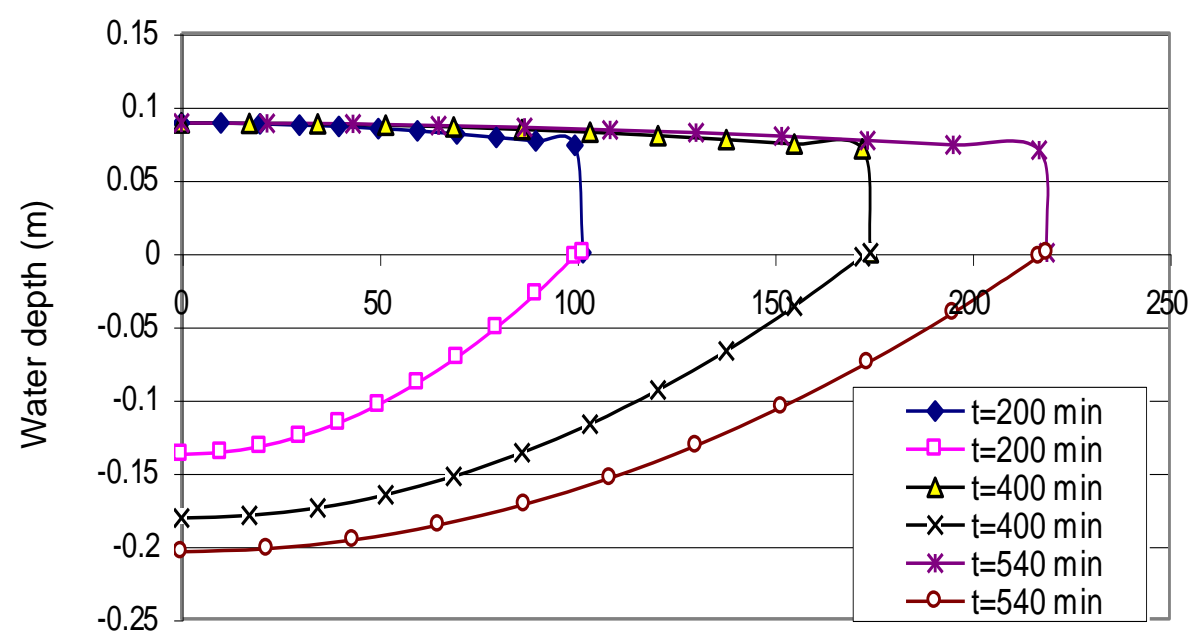

Advance distance $(\mathrm{m})$

Fig. 4. Surface and subsurface water profiles at different propagation time for the second border experiment.

Alvarez [19]. Three discharges were tested at each location. Table 1 presents the details of the four sites and the advance parameters. In each of the twelve experiments, sets consisting of three furrows were evaluated. The discharge applied to the central furrow of each set was measured with a Parshall flume installed at the upstream end. 
Table 1. Main characteristics of furrow experiments.

\begin{tabular}{ccccc}
\hline Site & 1 & 2 & 3 & 4 \\
\hline Slope $(\mathrm{m} / \mathrm{m})$ & 0.002 & 0.00092 & 0.0030 & 0.0012 \\
Furrow spacing (m) & 1.6 & 1.6 & 1.6 & 1.6 \\
Furrow length (m) & 240.0 & 380.0 & 333.0 & 333.0 \\
$p_{1}$ & 0.529 & 0.4632 & 0.508 & 0.522 \\
$p_{2}$ & 1.337 & 1.333 & 1.327 & 1.333 \\
Manning's n & 0.02 & 0.04 & 0.03 & 0.02 \\
Discharge (L/s) & $2.0,3.0,4.0$ & $3.2,6.6,7.5$ & $2.0,3.0,4.0$ & $3.0,4.0,5.0$ \\
\hline
\end{tabular}

To show the applicability of the model for furrow irrigation advance distance computation, in Figs. 5 to $\mathbf{8}$, values of advance distance are drawn versus the propagation time for different discharges. Also, on the same figures, the field values are compared with the computed ones by the model and it is shown the well agreement between the two. It is noticeable from these figures that the advance distance increases by increasing the discharge at the same time of propagation.

Figures 9 to 11 show the longitudinal surface and subsurface water profiles for furrow site 1 at different times for discharges 2,3 , and $4 \mathrm{~L} / \mathrm{s}$ respectively. It is noticeable that the volume of stored surface water is high compared with border irrigation where the stored volume nearly equal to the infiltrated volume. In comparison between these figures, it can be shown from these figures that infiltrated depth increases by increasing of discharges without regard to the time of propagation at the same advance distance. Also, from these figures, it is shown the rapidly varied flow region near the advance front.

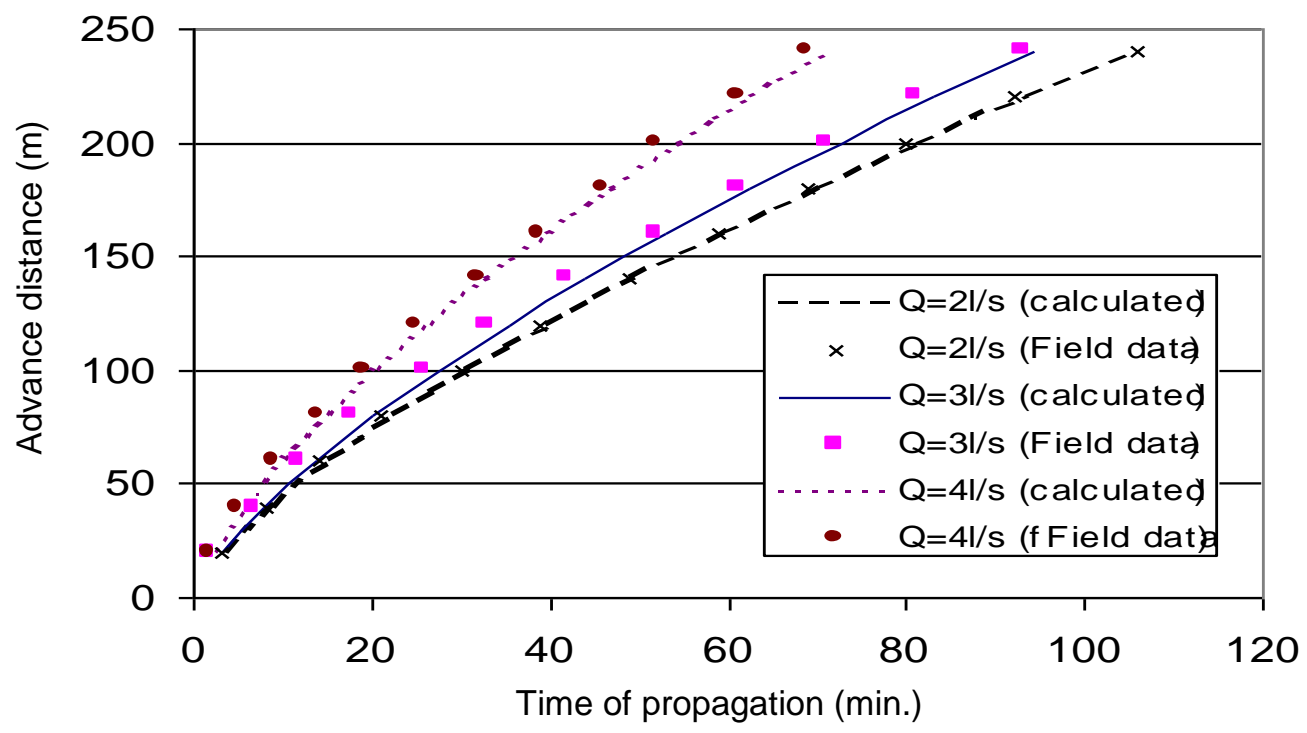

Fig. 5. Advance distance versus time of propagation for the first furrow irrigation field experiment at different discharges. 


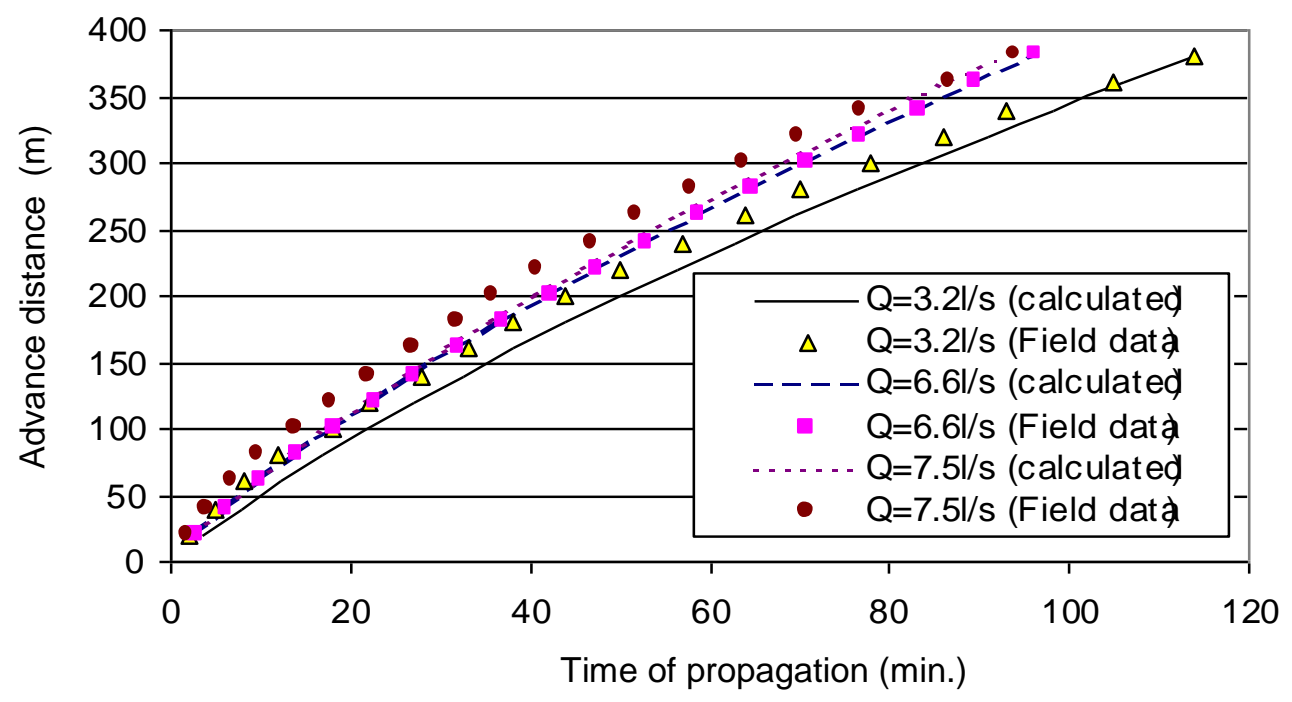

Fig. 6. Advance distance versus time of propagation for the second furrow irrigation field experiment at different discharges.

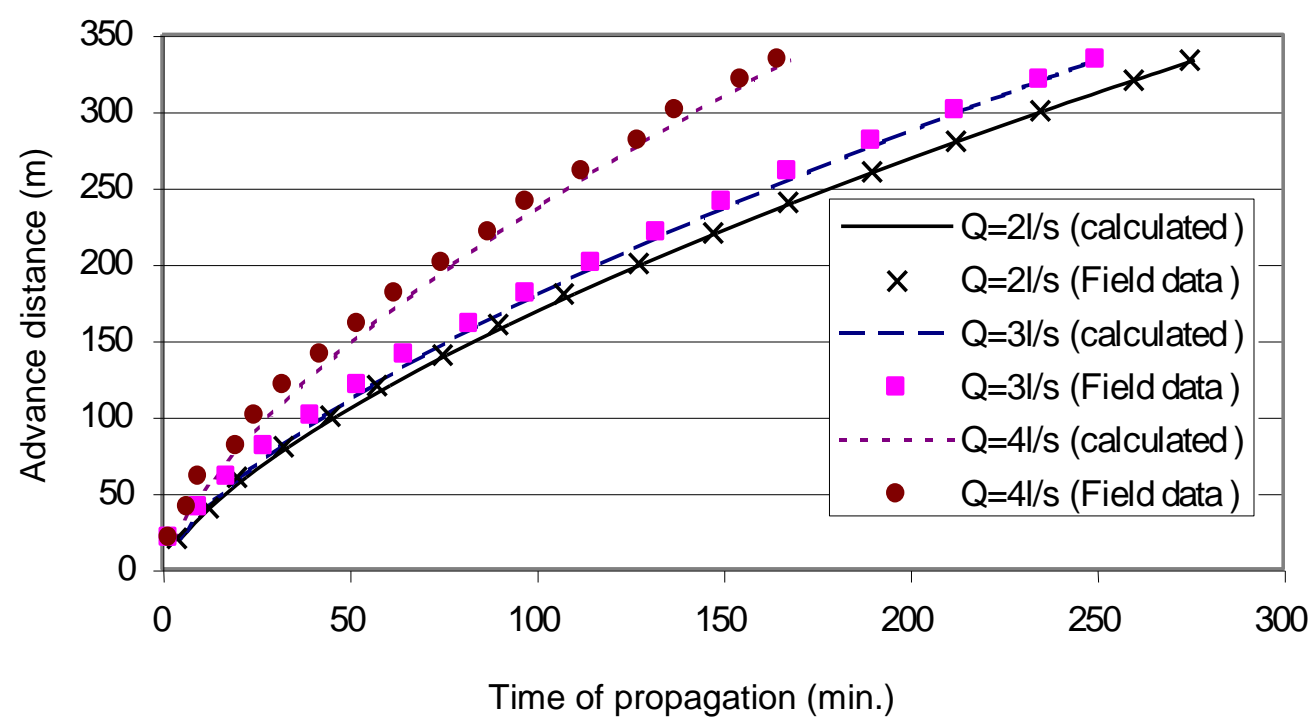

Fig. 7. Advance distance versus time of propagation for third furrow irrigation field experiments at different discharges. 


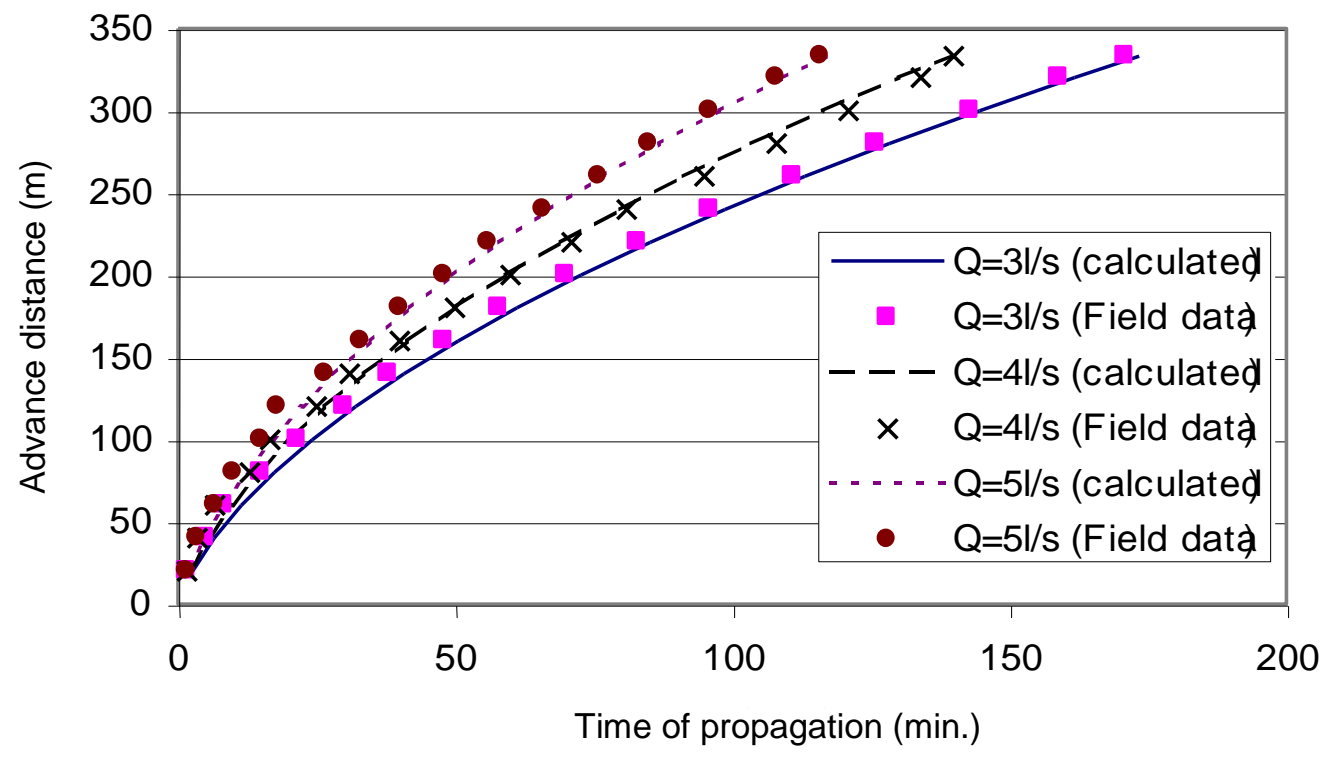

Fig. 8. Advance distance versus time of propagation for fourth furrow irrigation field experiment at different discharges.

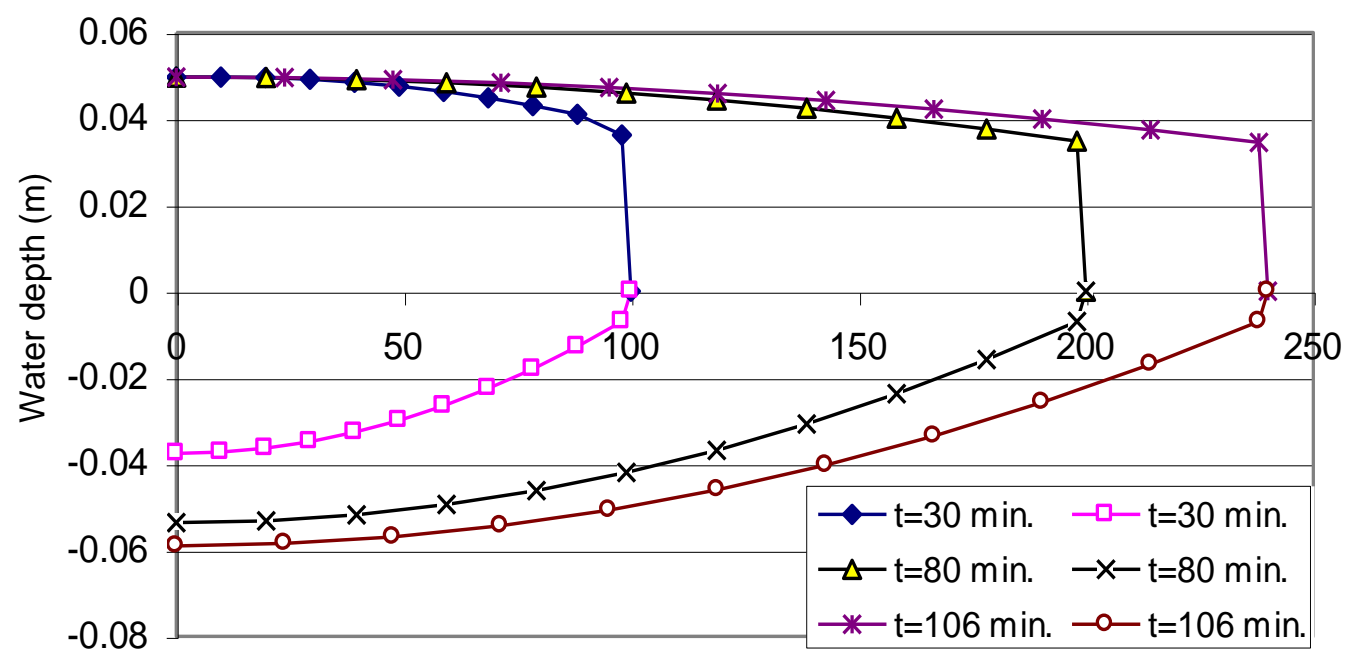

Advance distance $(\mathrm{m})$

Fig. 9. surface and subsurface water profiles at different propagation times for discharge $=2 \mathrm{~L} / \mathrm{s}$ and furrow site 1 . 


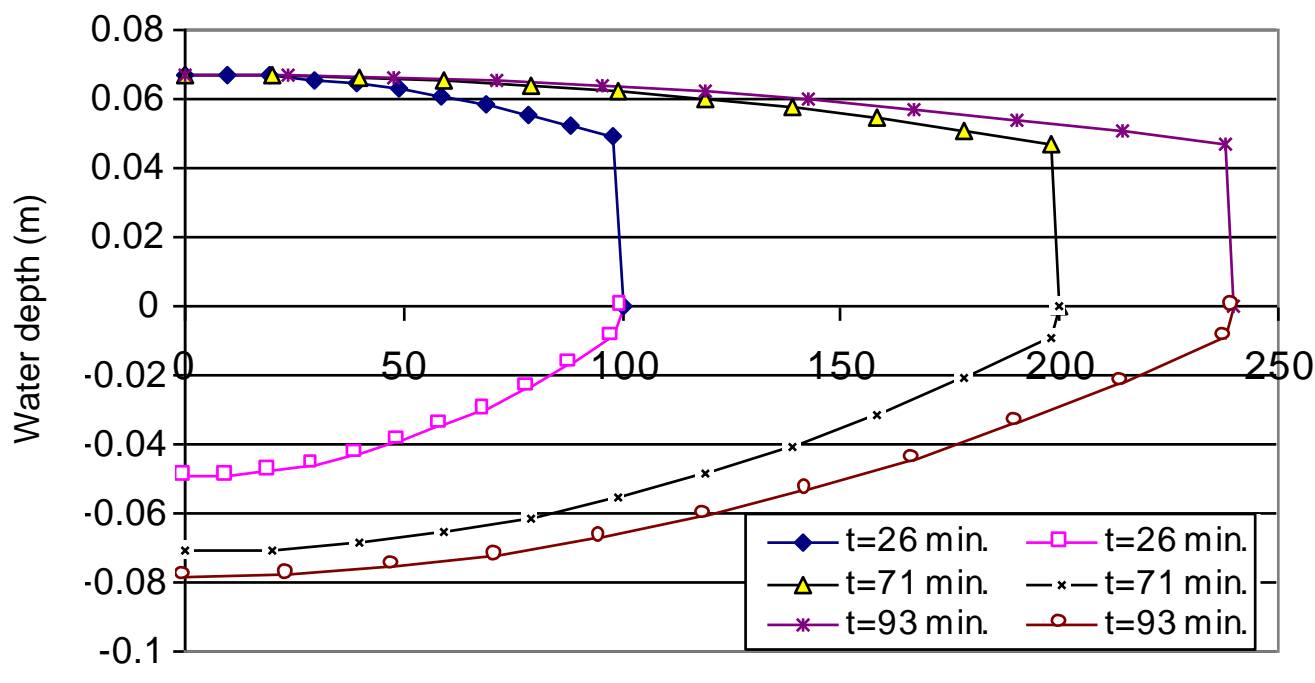

Advance distance (m)

Fig. 10. surface and subsurface water profiles at different propagation times for discharge $=3 \mathrm{~L} / \mathrm{s}$ and furrow site 1 .

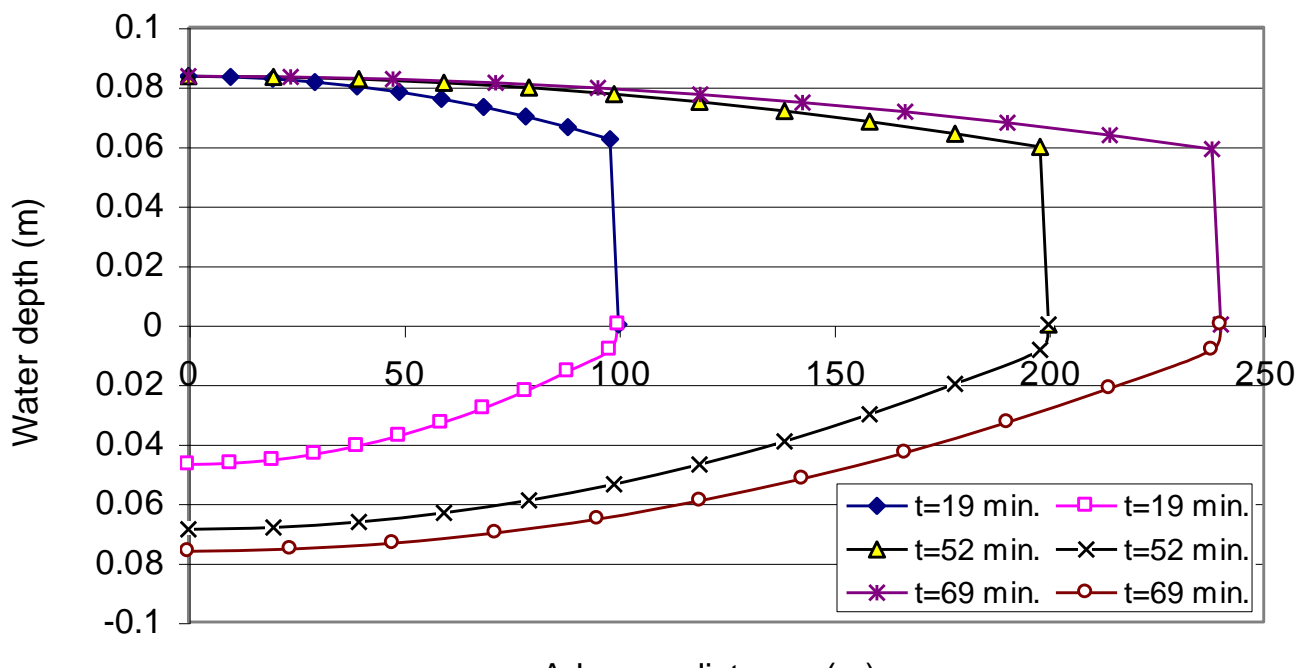

Advance distance $(\mathrm{m})$

Fig. 11. surface and subsurface water profiles at different propagation times for discharge $=4 \mathrm{~L} / \mathrm{s}$ and furrow site 1 .

\section{CONCLUSIONS}

Advance flow characteristics are one of the most subjects in the design and management of surface irrigation, particularly for the future automation of surface irrigation. 
In the present analysis, a method is developed for propagation time estimation based on the assumption that the water advance curve is gradually varied and follow a parabolic equation for both border and furrow irrigation and this will be useful in evaluation of irrigation methods. The present model can predict two aspects: The advance curve and longitudinal surface depth profile. The effectiveness of the procedure is shown by various problems, where the results are compared to experimental data. Where, six independent sets of border and furrow evaluation data have demonstrated the validity of the proposed method. It is found from this study that the field bed slope have a large effect on the advance distance and propagation time but it must be checked that its value is lower than the critical value for soil erosion. The model has the capability to predict the water surface profile at any time during the propagation. Programming requirements and computation time of the present method are significantly less compared with other sophisticated methods. The different parameters controlling irrigation process must be optimized to minimize volume of applied to the field.

\section{REFERENCES}

[1] Hauke, G. (2002). "A stabilized finite element method for the Saint-Venant equations with application to irrigation”, Int. Jour. Meth. Fluids, 38, 963-984.

[2] Strelkoff, T. S., and Bjorneberg, D. L. (1999). "Hydraulic modeling of irrigationinduced furrow erosion", $10^{\text {th }}$ International Soil Conservation Organization Meeting, 24-29 May, 1999, Purdue University, USA.

[3] Nasseri, A., Neyshabori, M. R., Fard, A. F., Mogaddam, M. and Nazemi, A. H. (2004). "Field-Measured furrow infiltration functions", Turk. J. for Agric., 28, 93-99.

[4] Abbasi, F., Feyen, J., and van Genuchten, M. Th. (2004). "Two-dimensional simulation of water flow and solute transport below furrows: model calibration and validation", Jour. of Hydrology, 290, 63-79.

[5] Rasoulzadeh, A., and Sepaskhah, A. R. (2003). "Scaled infiltration equations for furrow irrigation", Biosystms Engineering, 86 (3), 375-383.

[6] Eldeiry, A., Garcia, L., El-Zahar, A. S. A., and kiwan, M. E. (2004). "Furrow irrigation system design for clay soils in arid regions", Hydrology days 2004.

[7] Esfandiari, M., and Maheshwari, B. L. (2001). "Field evaluation of furrow irrigation models." J. Irrig. and Drain. Engrg., ASCE, 79(4), 459-479.

[8] Valiantzas, J. D. (1997). "Surface irrigation advance equation: variation of subsurface shape factor." J. Irrig. and Drain. Engrg., ASCE, 123(4), 300-306.

[9] Valiantzas, J. D. (1997). "Volume balance irrigation advance equation: variation of surface shape factor." J. Irrig. and Drain. Engrg., ASCE, 123(4), 307-312.

[10] Playán, E., Walker, W. R., and Merkley, G. P. (1994). "Two-Dimensional simulation of basin irrigation. I: Theory." J. Irrig. and Drain. Engrg., ASCE, 120(5), 837-855.

[11] Playán, E., and Garcia-Navarro, P. (1997). "Radial flow modeling for estimating level-basin irrigation parameters." J. Irrig. and Drain. Engrg., ASCE, 123(4), 229-237. 
[12] Zapata, N., and Playán, E. (2000). "Simulating elevation and infiltration in levelbasin irrigation.” J. Irrig. and Drain. Engrg., ASCE, 126(2), 78-84.

[13] Clemmens, A. J. (1992). "Feedback control of basin-irrigation system." J. Irrig. and Drain. Engrg., ASCE, 118(3), 480-496.

[14] Holzapfer, E. A., Jara, J., Zuñiga, C., Mariño, M. A., Paredes, J. and Billib, M. (2004). "Infiltration parameters for furrow irrigation." Agri. Water Management, $68,19-32$.

[15] Maheshwari, B. L., and McMahon, T. A. (1992). "Modeling shallow overland flow in surface irrigation.” J. Irrig. and Drain. Engrg., ASCE, 118(2), 201-217.

[16] Li, Z., and Zhang, J. (2001). "Calculation of field Manning's roughness coefficient.” Agri. Water Management, 49, 153-161.

[17] Yu, F. X., and Singh, V. P. (1989). "Analytical model for border irrigation." J. Irrig. and Drain. Engrg., ASCE, 115(6), 982-999.

[18] Playán, E., and Walker, W. R. (1994). "Two-Dimensional simulation of basin irrigation. II: Applications.” J. Irrig. and Drain. Engrg., ASCE, 120(5).

[19] Alvarez, J. A. R. (2003). "Estimation of advance and infiltration equations in furrow irrigation for untested discharges", Agri. Water Management, 60, 227-239.

\section{دراسة للسريان الضحل فوق قاع مسامي وبالأخص الري السطحي}

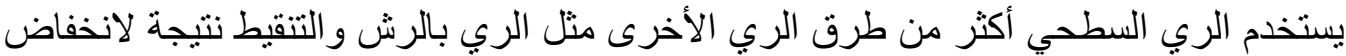

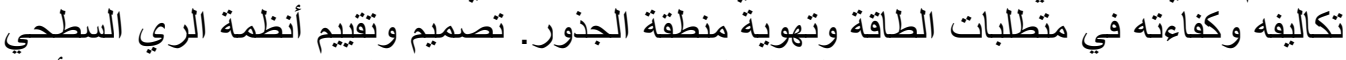
يعتمد على معرفة حركة المياه خلال الحقل. ومع ذلك فان هيدروليكية الري السطحي أكثر الكئ

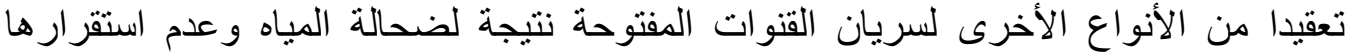

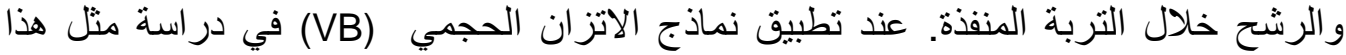

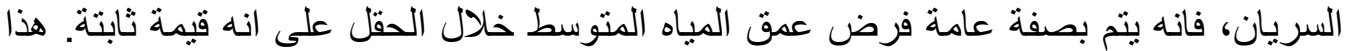
الفرض الأساسي قد يسبب أخطاء ملحوظة في حساب تقدم المياه خلال الحقل والزمن فئ اللازم

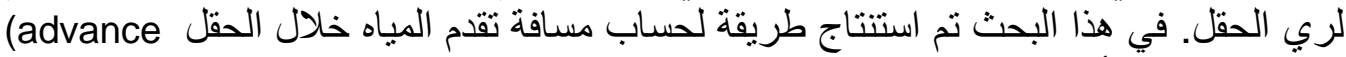
distance) الأحو اض وري الأخاديد. حيث أنه تم فرض أن منحنى سطح المياه للسريان فوق سطح الأرض

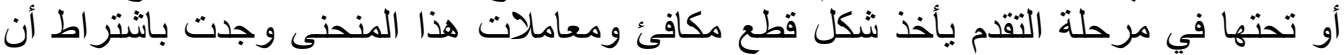

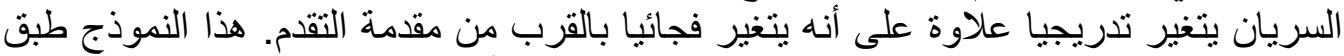

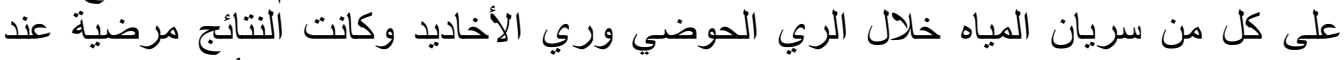

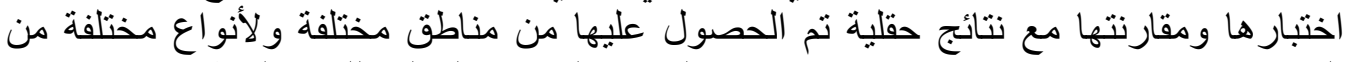

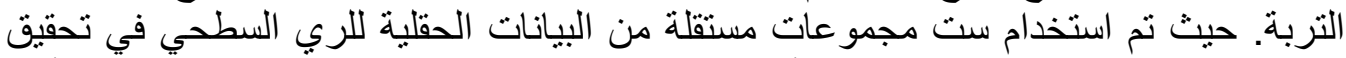
هذا النموذج. ووجد من هذه الدراسة أن ميل سطح الحقل والتصرف الته الداخل للحقل لَّات تأثير

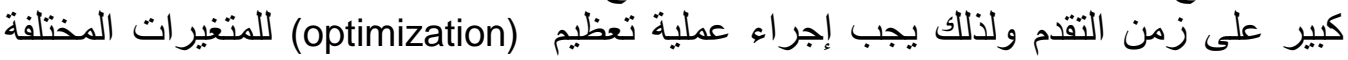
للوصول إلى اقل كمية مياه مستهلكة. متطلبات البرمجة وزمن الحسابات لهذه الطريقة اقل مقارنة بالطرق الأخرى الأكثر تعقيدا. 